\title{
One face, two facets: the Modern Greek complex prepositions brosta se and brosta apo
}

\author{
Zaphira Rohde \\ University of Heidelberg, Germany \\ https://doi.org/10.36505/ExLing-2012/05/0025/000231
}

\begin{abstract}
Languages differ substantially in the spatial concepts they choose to encode (Talmy 2000, Levinson 2003). This pilot study explores concepts related to the transversal (FRONT/BACK) axis in Modern Greek. As opposed to languages such as English (in front of) or German (vor), Greek allows two grammaticalized options for the localization of an entity in the front half-axis: the complex prepositions brosta se and brosta apo. Contrary to recent semantic analyses of Greek prepositions (Bortone 2010), our findings show that these options are not semantically equivalent. More specifically, our production data indicates that, within the complex preposition, the morphemes se and apo may mark distinct viewpoints on the same front subspace, a view that has been previously argued based on corpus data (Skopeteas 1999).
\end{abstract}

Key words: spatial cognition, spatial prepositions, front half- axis, Modern Greek.

\section{Introduction}

Crosslinguistic research on the semantics of spatial expressions has shown that the diversity found in the languages of the world depends on biological, typological and cultural factors (Talmy 2000, Levinson 2003).

FRONT, in particular, relates to the human physiology and to forward motion - it is relevant to the concept of direction and to the line of sight. Languages vary in the way they structure FRONT: a figure entity may be located in the FRONT subspace of a ground entity ${ }^{1}$, either in an ego-facing way involving reflection (i.e. the strategy followed by English speakers) or in an ego-aligned way involving translation ${ }^{2}$ (i.e. the strategy followed by speakers of Hausa; Hill 1982). In the facing strategy the figure is between the speaker and the ground; in the aligned strategy, the figure is the furthest away from the speaker.

Furthermore, localizing an entity in the front axis of another entity can vary regarding the viewpoint: speaker-anchored or ground-related. We talk about deictic localization, when the zero point of the coordinate axes - the so-called origo - is anchored on the speaker; if the ground figures as origo, we talk about intrinsic localization (Levelt 1996). In languages such as German, which only offer one grammaticalized option for FRONT (i.e. the spatial preposition vor), there are situations, in which deictic and intrinsic perspectives concur, resulting in ambiguity (Grabowski, 1994).

Modern Greek is interesting in its use of two options for the localization of an entity in the FRONT axis: the complex prepositions brosta se and brosta apo. Some scholars regard these as equivalent (free variation;

ExLing 2012: Proceedings of 5th Tutorial and Research Workshop on Experimental Linguistics, 27-29 August 2012, Athens, Greece 
Bortone2010), while others, based on corpora data, argue that these are different perspectives on the same subspace (Skopeteas 1999). Our empirical approach looks at usage and thus aims to fill the gap by providing actual production data.

\section{Method}

The present pilot study explores how Modern Greek speakers structure the front half-axis. The production experiment was carried out with 19 adult native speakers of Modern Greek (10 females, 9 males) using black and white photographs of playmobil figures and furniture, as well as other toys (vehicles, animals and houses). Photographs always included two objects and or figures/animals, one of which was marked by a red dot. Subjects were instructed to locate the entity with the red dot in relation to the second entity on the photo. The stimuli included 42 critical items and 30 fillers. Fillers comprised of spatial relations other than FRONT.

Subjects saw stimuli on a computer screen for two seconds; subsequently the screen turned blank (white) and they had six seconds to respond. The experiment was quasi self-paced, as subjects had to then press $\langle$ ENTER> to continue with the next stimulus.

\section{Results and Discussion}

Our empirical data indicates that within the complex preposition, the morphemes se and apo may mark distinct viewpoints on the same FRONT subspace. Overall, the study shows that brosta apo vs. brosta se are not semantically equivalent, brosta apo being the preferred option for the localization in the front half-axis ( $2 / 3$ of all data vs. $1 / 3$ brosta se). In cases of alignment between figure and ground, brosta apo usage rose to $90 \%$. Moreover, there seem to be more constraints on brosta se: usage of brosta se was most frequent in spatial arrays where figure and ground were facing each other, for example, a chair facing the front side of a closet $(55 \%)$ or arrays in which the figure had no inherent intrinsic orientation, such as a ball in front of a car $(45 \%)$.

The production data suggests that Greek speakers may follow an alignment strategy; future studies will test this hypothesis and check for any languagespecific effects (Levinson 2003).

Our study also questioned whether the distance between figure and ground plays a role for the selection of brosta se vs. brosta apo. As results on this issue were not clear, more research is required.

A significant gender factor was found in the usage of brosta se (72\% male vs. $28 \%$ female). Our data suggests that this may be due to differences in scene conceptualization. Subsequent research will, therefore, look into these 
One face, two facets: Greek propositions brosta se and brosta apo 103

grammatical categories and how they relate to speakers' perspective choice holistic, external vs. specific, internal.

Overall, our findings indicate that the spatial concepts encoded by brosta apo vs. brosta se in Modern Greek may be more complex than is suggested by the existing literature on frames of reference (Levelt 1996; Levinson 1996). More research is being conducted to unravel the actual concepts behind these morphological categories.

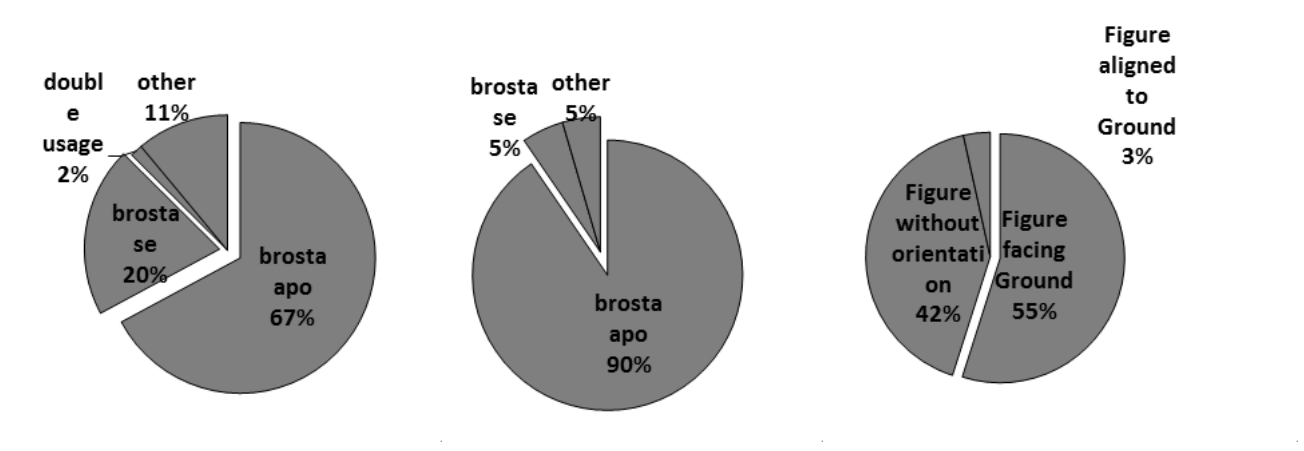

Figure 1. Frequency distribution of the complex prepositions brosta se and brosta apo. The first column shows the distribution overall. As shown in the second column, brosta apo is by far the preferred option when the figure is aligned to the ground. Finally, the third column shows that brosta se usage primarily occurred in constellations in which the figure had either no inherent orientation, or was facing the ground.

\section{Notes}

1. The terms figure and ground are used here after Talmy $(1983 ; 2000)$ and refer to the two participants of the prototypical spatial relation: the object to be located (figure) and the object which serves as a reference for the location (ground). Other terms used in the literature are theme versus relatum (Becker/Carroll 1997) and trajector versus landmark (Langacker 1990).

2. In cases of reflection (engl. in front of; ger. vor), the FRONT/BACK axis is mirrored, so that front is toward the speaker, and back is furthest away from the speaker, while right/left remain unchanged. In cases of translation (as in Hausa), back is towards the speaker, front is furthest away from the speaker.

\section{Acknowledgements}

I wish to thank Mary Carroll and Stavros Skopeteas for their precious advice on this study. Furthermore, I would like to thank Eva Soroli, Karin Fast and Johannes Gerwien for much help, fruitful discussions and feedback. 


\section{References}

Bortone, P. 2010. Greek Prepositions From Antiquity to the Present. Oxford University Press.

Grabowski, J. 1994. Kommunikative Unschärfen - Zur Rezeption und Produktion von Richtungspräpositionen am Beispiel vo "vor" und "hinter". In Kornadt, H.-J., Grabowski, J. and Mangold-Allwin, R. (eds.) Sprache und Kognition: Perspektiven moderner Sprachpsychologie. Heidelberg: Spektrum Akademischer Verlag.

Hill, C. 1982. Up/down, front/back, left/right. AContrastive Study of Hausa and English. In Weissenborn, J. and Klein, W. (eds.) 1982, Here and There. Amsterdam/Philadelphia: John Benjamins.

Levelt, W.J.M. 1996. Perspective Taking and Ellipsis in Spatial Descriptions. In Bloom, P., Peterson, M., Nadel, L. and Garrett, M. (eds.) Language and Space. MIT Press.

Levinson, S.C. 1996. Frames of Reference and Molyneux's Question: Crosslinguistic Evidence. In Bloom, P., Peterson, M., Nadel, L. and Garrett, M. (eds.) Language and Space. MIT Press.

Levinson, S.C. 2003. Space in Language and Cognition. Cambridge University Press.

Skopeteas, S. 1999. MG spatial relators with the Proper Prepositions /se/ and /apo/. In Moser, A. (ed.) Proceedings of the International Conference on Greek

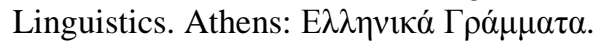

Talmy, L. 2000. Toward a cognitive semantics. Vol. II: Typology and process in concept structuring. Cambridge, Mass./London, England: MIT Press. 